\title{
Research on the Control Strategy of the Inter-provincial Electromagnetic Loop Network in Hubei Power Grid
}

\author{
Haiguang Liu*, Defu Cai , Chu Zhou, Kan Cao, Wentao Huang and Hang Dong \\ State Grid Hubei Electric Power Research Institute, Wuhan 430077, Hubei Province, China \\ ${ }^{*}$ Corresponding author
}

\begin{abstract}
Hubei-Henan transmission section is the first $1000 \mathrm{kV} / 500 \mathrm{kV} / 220 \mathrm{kV}$ three-level electromagnetic loop network in China and the most complex loop network in Hubei. According to the present situation of Hubei-Henan transmission section and Hubei-Hunan transmission section electromagnetic loop, the characteristics of the electromagnetic loop network between provinces and the problems that it brings to the security and stability of Hubei grid are analyzed. With the network structure characteristic of Hubei Grid considered, the exiting problems are studied and the corresponding control strategies are proposed. This work can provide certain practical value for the operation of the inter-provincial transmission sections in Hubei grid.
\end{abstract}

Keywords-inter-provincial transmission section;electromagnetic loop network; load flow characteristics; security and stability

\section{INTRODUCTION}

Electromagnetic loop network refers to the power grid in which the transmission lines of different voltage-levels are parallel operated through the transformers' electromagnetic circuit. When the high voltage-level transmission lines of the electromagnetic loop break down, its flow runs through to the low voltage level lines, causing that the transformers and transmission lines overload. The inter-provincial sections undertake the task of power balance and exchange between provinces with heavier load flow, and so the inter-provincial electromagnetic loop is more harmful.

The electric generating feature of Hubei grid is "more hydropower generator capacity, less thermal generator capacity", which causes that the flow direction of the interprovincial section in wet season is different from that of the dry season. Hubei-Henan transmission section is the first $1000 \mathrm{kV} / 500 \mathrm{kV} / 220 \mathrm{kV}$ three-level electromagnetic loop network, resulting in the complexity of the inter-provincial electromagnetic loop in Hubei.

According to the present situation of Hubei-Henan transmission section and Hubei-Hunan transmission section electromagnetic loop, the formation of inter-provincial electromagnetic network and the problems that it brings to the stability and security of Hubei grid are analyzed. The control strategies are proposed to solve the problems in existence when there are not enough conditions to unlock the interprovincial electromagnetic loop, and its effect is verified.

\section{FORMATION OF THE ELECTROMAGNETIC LOOPS}

Without $220 \mathrm{kV}$ transmission line between Hubei power grid and its neighboring provinces, the electromagnetic loops between provinces are formed as $500 \mathrm{kV}$ substation access into inter-provincial section in $\pi$-mode. The schematic diagram of the electromagnetic loop between Hubei and Henan is as Figure I.

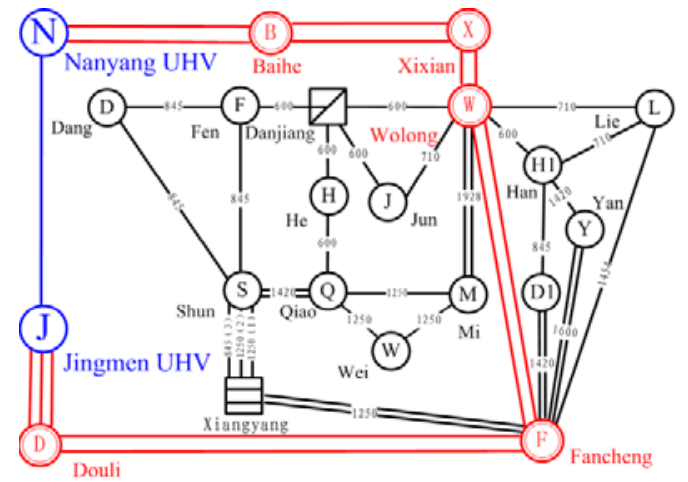

FIGURE I. THE STRUCTURE OF HUBEI-HENAN LECTROMAGNETIC LOOP

Before $500 \mathrm{kV}$ Wolong substation access into Hubei grid, Hubei-Henan transmission section is composed by $500 \mathrm{kV}$ line Fan-Xi I/II, line Xiao-Shi I/II and 1000kV UHV line Nan-Jing $\mathrm{I}$, forming inter-provincial $1000 \mathrm{kV} / 500 \mathrm{kV}$ electromagnetic loop. Wolong substation is planned to go into operation between 2015 and 2016 by accessing into Fan-Xi I/II in $\pi$ mode with Fan-Xi I/II replaced by Fan-Wo I/II and Wo-Xi I/II, and the $1000 \mathrm{kV} / 500 \mathrm{kV} / 220 \mathrm{kV}$ electromagnetic loop between Hubei and Henan is formed. When $1000 \mathrm{kV}$ or $500 \mathrm{kV}$ transmission line break down, part of its load flow transfer to $220 \mathrm{kV}$ grid, causing that the transmission lines neighboring $500 \mathrm{kV}$ Fancheng and Wolong substations take the risk of overload.

Similar to Hubei-Henan transmission section loop, the electromagnetic loop between Hubei and Hunan was formed after Chanling substation accessed into $500 \mathrm{kV}$ line Jiang-Fu $\mathrm{I} / \mathrm{II}$ in $\pi$-mode in 2014, as Figure II. 


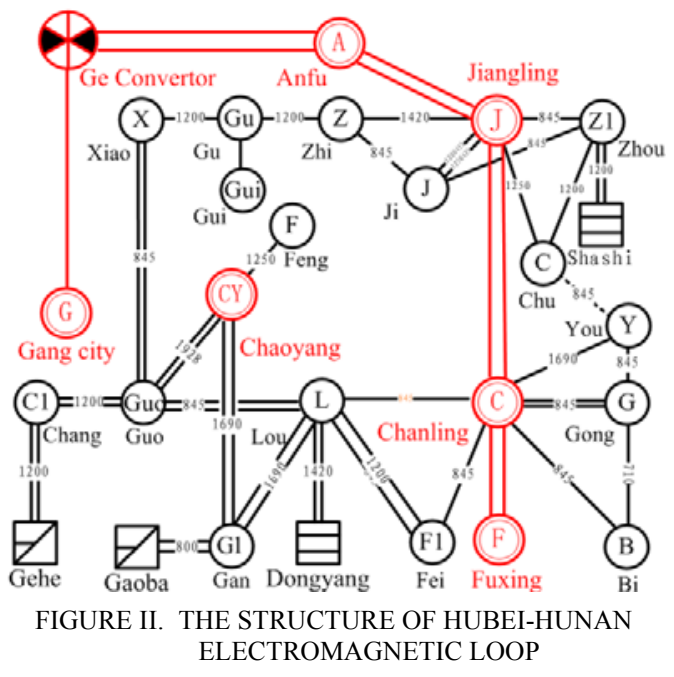

There was no transfer flow to $220 \mathrm{kV}$ grid when Jiang-Fu I/II break down before Chanling accessed into the network, and all the power flow of the section poured into $500 \mathrm{kV}$ line Ge-Gang. After $500 \mathrm{kV}$ Chanling substation accessed into Hubei grid, Hubei-Hunan transmission channel changes from Jiang-Fu I/II + line Ge-Gang to Jiang-Chan I/II and Chan-Fu $\mathrm{I} / \mathrm{II}+\mathrm{Ge}-\mathrm{Gang}$, forming the inter-provincial $500 \mathrm{kV} / 220 \mathrm{kV}$ electromagnetic loop. Compared to the network without Chanling, the conclusion keeps unchanged when Chan-Fu I/II break down, but the power flow transfer to $220 \mathrm{kV}$ network via Yichang grid when Jiang-Chan I/II is cut off.

\section{The Problems of Electromagnetic Loops}

\section{A. Hubei-Henan Section Electromagnetic Loop}

When $500 \mathrm{kV}$ Fan-Wo I/II is disconnected due to line failure, $18 \%, 39 \%$ of its flow transfer to Xiao-Shi I/II and Nan-Jing I. The line-style of Nan-Jing I is LGJ- $8 \times 500$ of which the power limit is $8000 \mathrm{MW}$, and the load flow of XiaoShi I/II is very light, so there is no risk of overload for $500 \mathrm{kV}$ and $1000 \mathrm{kV}$ network during the post-fault of Fan-Wo I/II.

$43 \%$ of the flow pours into $220 \mathrm{kV}$ network, causing Fancheng substation and lines connected risk overload during the wet season; Wolong substation and lines connected risk overload during the dry season similarly. The transfer ratios of important $500 \mathrm{kV}$ substations are shown in Table I.

\section{TABLE I. TRANSFER RATIO OF FAN-WO I/II POST-FAULT}

\begin{tabular}{|c|c|c|c|}
\hline Component & Transfer ratio/\% & Component & $\begin{array}{c}\text { Transfer } \\
\text { ratio/\% }\end{array}$ \\
\hline Wolong & -43.1 & Qiao-Shun I & 11.9 \\
\hline Fancheng & 38.9 & WO-Mi I & -12.8 \\
\hline Shiyan & 7.3 & Line Wo-Dan & -3.3 \\
\hline Xiaogan & -1.4 & Line Wo-Han & -9.2 \\
\hline Xiang-Shun I & 7.9 & Line Wo-Lie & -3.7 \\
\hline $\begin{array}{c}\text { Xiang-Shun } \\
\text { III }\end{array}$ & 6.3 & Line Fen-Dang & 5.3 \\
\hline
\end{tabular}

In the initial power flow of the wet season, all the hydropower and thermal units start up and Fan-Wo I/II transmit $2000 \mathrm{MW}$ to Henan. The power flow of the important $220 \mathrm{kV}$ components during the pre-fault and post-fault is shown in Table II.

TABLE II. FLOW COMPARISON OF PRE AND POST FAULT IN WET SEASON

\begin{tabular}{|c|c|c|c|}
\hline Component & $\begin{array}{c}\text { Pre- } \\
\text { fault/MW }\end{array}$ & Post-fault/MW & Power limit/MW \\
\hline Wolong \#1 & 83 & -348 & 935 \\
\hline Fancheng \#2 & 332 & 784 & 935 \\
\hline Xiang-Shun III & 193 & 319 & 280 \\
\hline Qiao-Shun I & 263 & 502 & 460 \\
\hline Line Fen-Dang & 145 & 251 & 280 \\
\hline
\end{tabular}

In the case of Fan-Wo I/II failure, $38.9 \%$ of the power flow transfer to the coupling transformers in Fancheng, leading to that the load flow of Fancheng \#2 transformer reaches $784 \mathrm{MW}$. It risk overload when Xiangyang power plant and Danjiang power plant start up less units. E.g. only two units of Xiangyang and four units of Danjiang start up and the load flow of Fancheng \#2 transformer reaches overload 941MW in the post-fault duration of Fan-Wo I/II.

In the $220 \mathrm{kV}$ network, both Xiangyang plant and Fancheng substation supply power for Qiaoying, Mizhuang and Weizhuang in the load center of Xiangfan grid through $220 \mathrm{kV}$ line Xiang-Shun I/II/III. 22.1\% of the pre-fault flow transfer to Xiang-Shun I/II/III when Fan-Wo I/II break down, causing that Xiang-Shun III and Qiao-Shun I/II overload.

Besides, part of the flow transfer to the $220 \mathrm{kV}$ transmission lines between $500 \mathrm{kV}$ Shiyan substation and $500 \mathrm{kV}$ Wolong substation. Among them, the transfer ratio of line Fen-Dang is up to $5.3 \%$, leading to that its power flow reaches 251MW approaching the limit. If two units of Danjiang are turned off on the basis of the initial power flow, the flow of line Fen-Dang reaches 291MW overload when Fan-Wo I/II break down.

In the initial power flow of the dry season, Danjiang's net load is $250 \mathrm{MW}$ (power generated: $300 \mathrm{MW}$, load: $550 \mathrm{MW}$ ), and three units of Xiangyang start up, and the pre-fault flow of Fan-Wo I/II is $1000 \mathrm{MW}$ transmitted to Hubei. The power flow of the important $220 \mathrm{kV}$ components during the pre-fault and post-fault is shown in Table III.

TABLE III. FLOW COMPARISON OF PRE AND POST FAULT IN DRY SEASON

\begin{tabular}{|c|c|c|c|}
\hline Component & $\begin{array}{c}\text { Pre- } \\
\text { fault/MW }\end{array}$ & Post-fault/MW & Power limit/MW \\
\hline Wolong \#1 & 548 & 771 & 935 \\
\hline Fancheng \#2 & 587 & 362 & 935 \\
\hline Line Wo-Dan & 156 & 190 & 200 \\
\hline Line Wo-Han & 100 & 196 & 220 \\
\hline Line Wo-Lie & 108 & 146 & 220 \\
\hline
\end{tabular}


There is no risk of overload for the coupling transformers of Wolong while the unit commitment changes in spite of that $43 \%$ of the pre-fault flow transfer to Wolong transformers.

According to Table III, line Wo-Dan and line Fan-Wo have been closed to their own limit when Fan-Wo I/II break down. Line Wo-Dan can easily get overload while Danjiang and Xiangyang plant start up less units. For example, the load flow of line Wo-Dan reaches 205MW overload if Danjiang plant's net load is $300 \mathrm{MW}$ and only two units of Xiangyang start up. Similarly, Line Wo-Han can easily get overload while Danjiang start up more units and Xiangyang start up less units, for example, the load flow of line Wo-Han reaches 224MW if Danjiang's net load is 0 and only two units of Xiangyang start up.

\section{B. Hubei-Hunan Section Electromagnetic Loop}

The power flow of Jiang-Chan I/II is transmitted from Hubei to Hunan both in wet season and dry season. Take the wet season as the initial power flow and the Hubei-Hunan section transmit $2600 \mathrm{MW}$ to Hunan. The post-fault transfer ratio of important $500 \mathrm{kV}$ substations and $220 \mathrm{kV}$ lines neighboring Chanling is shown in Table IV.

\section{TABLE IV. TRANSFER RATIO OF JIANG-CHAN I/II POST-FAULT}

\begin{tabular}{|c|c|c|c|}
\hline Component & Transfer ratio/\% & Component & $\begin{array}{c}\text { Transfer } \\
\text { ratio/\% }\end{array}$ \\
\hline Jiangling & 12.6 & Line Chan-Lou & 13.1 \\
\hline Chanling & -32.5 & Line Chan-Fei & 19.4 \\
\hline Chaoyang & 16.9 & Lou-Fei I & 11.1 \\
\hline Line Ge-Gang & 67.5 & Lou-Fei II & 8.3 \\
\hline
\end{tabular}

$67.5 \%$ of the pre-fault flow pours into $500 \mathrm{kV}$ line $\mathrm{Ge}-$ Gang, causing that its flow reaches 2162MW overload. $32.5 \%$ of the pre-fault flow transmitted from Jiangling and Chaoyang substations to Chanling substation via $220 \mathrm{kV}$ network, but there is no risk of overload for $500 \mathrm{kV}$ transformers in wet season. The $220 \mathrm{kV}$ network neighboring Chanling substation is weak affected by the transferred flow, and the load flow of Chan-Fei, Chan-Lou and Lou-Fei I/II is 518MW, 390MW, $405 \mathrm{MW}$, 304MW during the post-fault of Jiang-Chan I/II, all of these lines overload.

\section{RESEARCH OF THE CONTROL StRATEGIES}

\section{A. Restricting the Flow of the Section in Pre-fault}

If the transmission capacity of the inter-provincial section is adequate, adopting the strategy of restricting the flow of the section is the most direct and effective. Although the transfer ratio keeps unchanged with the decrease of the section flow, the amount of the transferred flow reduces.

Take the electromagnetic loop between Hubei and Henan as an example, and it can be ensured that Fan-Wo I/II won't get overload during the post-fault of Nan-Jing I while the power flow of the Hubei-Hunan section is limited between 4300MW northward and 5000MW southward.
To ensure that the flow of Hubei-Hunan section can satisfy the demand of Hunan's load, the transmitted power of the section can be limited to $2600 \mathrm{MW}$ at most. So other measures must be taken to restrict the power flow of Ge-Gang when Jiang-Chan I/II or Chan-Fu I/II break down.

\section{B. Load Shedding of the Receiving End in Post-fault}

If the flow of the section can't be restricted to a secure limit due to the demand of inter-provincial power exchange, the strategy of shedding load of the receiving end in post-fault can be adopted. Its essence is reducing the section flow during the post-fault under the premise of unchanging the section flow of pre-fault.

Keeping the power flow of Hubei-Hunan section 2600MW unchanged, $500 \mathrm{kV}$ line Ge-Gang get overload whether it is Chan-Fu I/II or Jiang/Fu I/II that break down. With the strategy of shedding load of Hunan $950 \mathrm{MW}$ in case of breakdown, the flow of line Ge-Gang can be controlled beneath its limit 1650MW

If $220 \mathrm{kV}$ transmission line get overload, the sequence of load shedding depends on the load sensitivity. To prevent $220 \mathrm{kV}$ line Wo-Han, Wo-Lie and Han-Lie from overload while Fan-Wo I/II break down in dry season, load shedding device is equipped in $220 \mathrm{kV}$ substation Hangang, Dongjin, Lieshan and Zengdu, the sensitivity of shedding 50MW load is shown in Table V.

TABLE V. LOAD SHEDDING SENSITIVITY OF XIANGFAN

\begin{tabular}{|c|c|c|c|c|}
\hline & Hangang & Dongjin & Lieshan & Zengdu \\
\hline Line Wo-Han & -14 & -5 & -3 & -3 \\
\hline Line Han-Lie & 9 & 3 & -7 & -7 \\
\hline Line Wo-Lie & -1 & -1 & -9 & -6 \\
\hline
\end{tabular}

For example, when Danjiang's net load is 0MW and two unit of Xiangyang plant start up in dry season, the flow of line Wo-Han reaches 224MW after Fan-Wo I/II's failure, shedding load of Hangang for 50MW can reduce the flow of Wo-Han to 210MW.

\section{Cutting off 500kV Transformers of the Receiving End in Post-fault}

Different from the strategies proposed above, cutting off the $500 \mathrm{kV}$ transformers of the receiving end changes the transfer ratio instead of the inter-provincial section flow (neither the pre-fault nor post-fault flow). More of the prefault flow transfer to $500 \mathrm{kV}$ and $1000 \mathrm{kV}$ network while the transfer ratio of $220 \mathrm{kV}$ network reduces. So this strategy is used to solve the problem of $220 \mathrm{kV}$ component's overload if the remaining $500 \mathrm{kV}$ and $1000 \mathrm{kV}$ transmission lines controllable. Two components of the network, the $500 \mathrm{kV}$ line that break down and the $500 \mathrm{kV}$ transformer of the receiving end, are lost if transformer is cut off as a strategy. The related flow transfer formula is as follow:

$$
\mathrm{P}_{\mathrm{C} 2}=\mathrm{P}_{\mathrm{C} 1}+\mathrm{a} \% \mathrm{P}_{\mathrm{A} 1}+\mathrm{b} \% \mathrm{P}_{\mathrm{B} 1}
$$


$\mathrm{P}_{\mathrm{Al}}, \mathrm{P}_{\mathrm{B} 1}, \mathrm{P}_{\mathrm{Cl}}$ represent the initial power flow of $\mathrm{A}, \mathrm{B}, \mathrm{C}$; $\mathrm{a} \%$ represents the transfer ratio of $\mathrm{A}$ to $\mathrm{C}$ in the case that $\mathrm{B}$ is unavailable; $\mathrm{b} \%$ represents the transfer ratio of $\mathrm{B}$ to $\mathrm{C}$ in the case that $\mathrm{A}$ is unavailable; $\mathrm{P}_{\mathrm{C} 2}$ represents the flow of $\mathrm{C}$ in the case that $\mathrm{A}$ and $\mathrm{B}$ break down or cut off simultaneously.

In wet season, Wolong substation transmits $700 \mathrm{MW}$ to $500 \mathrm{kV}$ network from $220 \mathrm{kV}$ network when Fan-Wo I/II break down. If the coupling transformers of Wolong are cut off in post-fault, the flow of $\mathrm{Wo}-\mathrm{Xi}$ is 0 and all the $700 \mathrm{MW}$ flow transfer to Nan-Jing I and Xiao-Shi I/II. Hubei-Henan section won't get overload in every operation mode while the strategy of cutting off transformers is adopted, so it's feasible for the electromagnetic loop between Hubei and Henan.

According to the definition of the transfer ratio in formula 1, the transfer ratio of Fan-Wo I/II (component A) and Wolong transformers ( component B) to the components in $220 \mathrm{kV}$ network (component $\mathrm{C}$ ) is shown in Table VI and VII.

TABLE VI. TRANSFER RATIO OF FAN-WO I/II POST-FAULT (WOLONG TRANSFORMERS UNAVAILABLE)

\begin{tabular}{|c|c|c|c|}
\hline Component & Transfer ratio/\% & Component & $\begin{array}{c}\text { Transfer } \\
\text { ratio/\% }\end{array}$ \\
\hline Fancheng & 17.8 & Xiang-Shun I & 1.2 \\
\hline Shiyan & 2.5 & Xiang-Shun III & 1.0 \\
\hline Xiaogan & -6.9 & Line Fen-Dang & 1.5 \\
\hline Qiao-Shun I & 1.1 & & \\
\hline
\end{tabular}

Compared to Table I, cutting off the transformers of Wolong can disconnect the $220 \mathrm{kV}$ electromagnetic loop, so the transfer ratio of Xiang-Shun I/II/III, Qiao-Shun and FenDang reduces to only about $1 \%$ when Fan-Wo I/II break down The transfer ratio of Fancheng is $17.8 \%$, but $6.5 \%$ of it transfer to $500 \mathrm{kV}$ Shuanghe substation through Jingmen grid and finally transfer to Xiao-Shi I/II through $500 \mathrm{kV}$ network without passing through Xiangfan grid.

TABLE VII. TRANSFER RATIO OF WOLONG TRANSFORMERS POSTFAULT (FAN-WO I/II UNAVAILABLE)

\begin{tabular}{|c|c|c|c|}
\hline Component & Transfer ratio/\% & Component & $\begin{array}{c}\text { Transfer } \\
\text { ratio/\% }\end{array}$ \\
\hline Fancheng & 45.5 & Xiang-Shun I & 12.3 \\
\hline Shiyan & 11.0 & Xiang-Shun III & 9.8 \\
\hline Xiaogan & 14.7 & Line Fen-Dang & 8.7 \\
\hline Qiao-Shun I & 23.4 & & \\
\hline
\end{tabular}

The side-effect of cutting off Wolong transformers is that the initial flow (before Fan-Wo I/II break down) of the transformer transfer to the other $500 \mathrm{kV}$ transformers and $220 \mathrm{kV}$ connecting lines. In case that the initial power flow is as in Table II, if Wolong transformers are cut off in post-fault, the power flow of Xiang-Shun III, Qiao-Shun I and line FenDang is 232MW, 324MW and 190MW, no overload.

\section{CONCLUSION AND PROSPECT}

According to the present situation of the existing electromagnetic loops, the problems they cause are researched and the control strategy is proposed.

1) In case that the transmission capacity of the interprovincial section is adequate, restricting the power flow of the section is effective. There is no risk of overload for $1000 \mathrm{kV} / 500 \mathrm{kV}$ electromagnetic loop while the power flow of the Hubei-Hunan section is limited between 4300MW northward and 5000MW southward.

2) The strategy of shedding load of the receiving end won't affect the transmission capacity of the inter-provincial section. The strategy of shedding load of Hunan 950MW can ensure that line Ge-Gang won't risk overload. The strategy of shedding load of Hangang, Dongjin, Lieshan, Zengdu 50MW each could solve the problem that Wo-Han, Wo-Lie, Han-Lie overload slightly when Fan-Wo I/II break down in dry season.

3) The strategy of cutting off transformers of receiving end is used to solve the problem of $220 \mathrm{kV}$ component's overload. Cutting off the coupling transformers of Wolong could solve the problem that Xiang-Fan III, Qiao-Shun I, line Fen-Dang get overload when Fan-Wo I/II break down in wet season. Cutting off Chanling transformer could solve the problem that Chan-Fei, Chan-Lou, Lou-Fei I/II get overload when JiangChan I/II break down.

When there are not enough conditions to unlock the electromagnetic loop network, the structure of the $220 \mathrm{kV}$ network can be optimized through planning. For example, when $220 \mathrm{kV}$ substation Zinan is put into operation in 2016, the problem of $220 \mathrm{kV}$ line overload can be solved without cutting off Chanling transformer.

\section{ACKNOWLEDGMENT}

This work was supported by the Project of State Grid Hubei Electric Power Company (52153214001J).

\section{REFERENCES}

[1] Chin Y Choo, Nirmal-Kumar C Nair,Bhujanga Chakrabarti. Impacts of Loop Flow on Electricity Market Design. Power System Technology. 2006. Power Con 2006. International Conference on Oct. 2006 page(s) : $1 \sim 8$.

[2] Hou Chunqing,Zheng Huiping. Research on Parallel Operation of 500kV and 220kV Power Networks in South and Central Part of Shanxi Power Grid in 2005 [J]. Power System Technology, 2005, 29(10):80-84.

[3] Zhang Zuping,Fan Mingtian,Zhou Limei. Research of Breaking up Electromagnetic Ring in Urban Power Network [J]. Power System Technology, 2008, 32(19): 42-44.

[4] Granelli G, Montagna M, Zanellini F, et al. A Genetic Algorithm-based Procedure to Optimize System Topology against Parallel Flows [J]. IEEE Trans on Power Systems, 2006, 21(1): 333-340.

[5] $\mathrm{Hu}$ yangyu, Fu Hongjun, Zhang Yiming, et al. Analysis on Electromagnetically Coupled Loop Operation of Tie Line Connecting Hubei Power Grid and Henan Power Grid after Building up of Nanyang UHVAC Substation [J].Power system Technology, 2011, 35(6):22-26.

[6] Liu Nan, Tang Xiaojun, Zhang wenchao, et al. Study on Electromagnetic Ring Opening in Henan Province under Ultrahigh Voltage Power Grid [J]. Power System Protection and Control, 2011, 39(2):131-1 